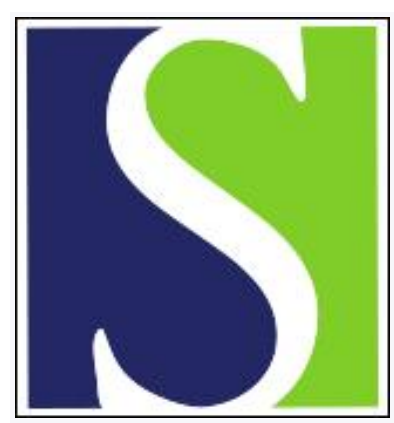

Scand J Work Environ Health 1990;16(6):443-444

https://doi.org/10.5271/sjweh.1761

Issue date: 01 Dec 1990

The Chernobyl accident and induced abortions: only one-way information.

by Perucchi M, Domenighetti G

This article in PubMed: www.ncbi.nlm.nih.gov/pubmed/2284594

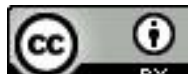


Scand J Work Environ Health 1990;16:443-4

\section{The Chernobyl accident and induced abortions: only one-way information}

In the study recently published by Bertollini et al (1), a reduced number of births and an increased number of induced abortions were observed in some regions of Italy after the Chernobyl nuclear accident.

In this letter, we report the main results of a similar study (2) conducted in the canton of Ticino (the Italianspeaking part of Switzerland) and point out a possible causal factor that seems to deserve more attention in the discussion of the induced-abortion results and consequent reduction in birth rate in relation to the Chernobyl event.

In Ticino we observed a $57.7 \%(\mathrm{P}<0.001)$ increase in the number of induced abortions in June 1986 (figure 1) in comparison with the four-year trend for 1984-1988, and a significant reduction in the number of births in the first two months of 1987 with respect to the secular trend, particularly in February $(15 \%$ reduction in the birth rate, $\mathrm{P}<0.05)$. For June 1986 we also found a significant reduction in the average number of days between the date of the request for an induced abortion and the surgical operation.

These results, in particular the reduction in the time lag between request and surgical operation, seem not only to suggest fear, anxiety, and panic among pregnant women [psychological distress from abortion generally being the greatest before the intervention (3)], but also uncertainty and confusion among physicians. We surveyed a sample of Ticino physicians and gynecologists and found that they were not aware of the relationship between low-radiation exposure and the risk of fetal abnormalities. In May 1986, we were unable to find a Ticino physician ready to explain this relation to the public on the Swiss Italian radio channel.

In Switzerland a special federal task force was implemented immediately after the Chernobyl accident to inform the population of how (particularly with dietary habits) to contain the possible adverse effects of the radioactive fall-out. The recommendations issued by this group indicated an increased risk especially for pregnant women. This information, which was given to the general population, repeatedly created a situation of panic, like a posttraumatic stress disorder, in those particular subjects. However, the federal task force neglected to give special information to the medical profession in general, and to gynecologists in particular, about the "state of the art" or a reasonable evaluation of the risk of fetal abnormalities following the Chernobyl fall-out in Switzerland, and in the canton of Ticino in particular - risk that

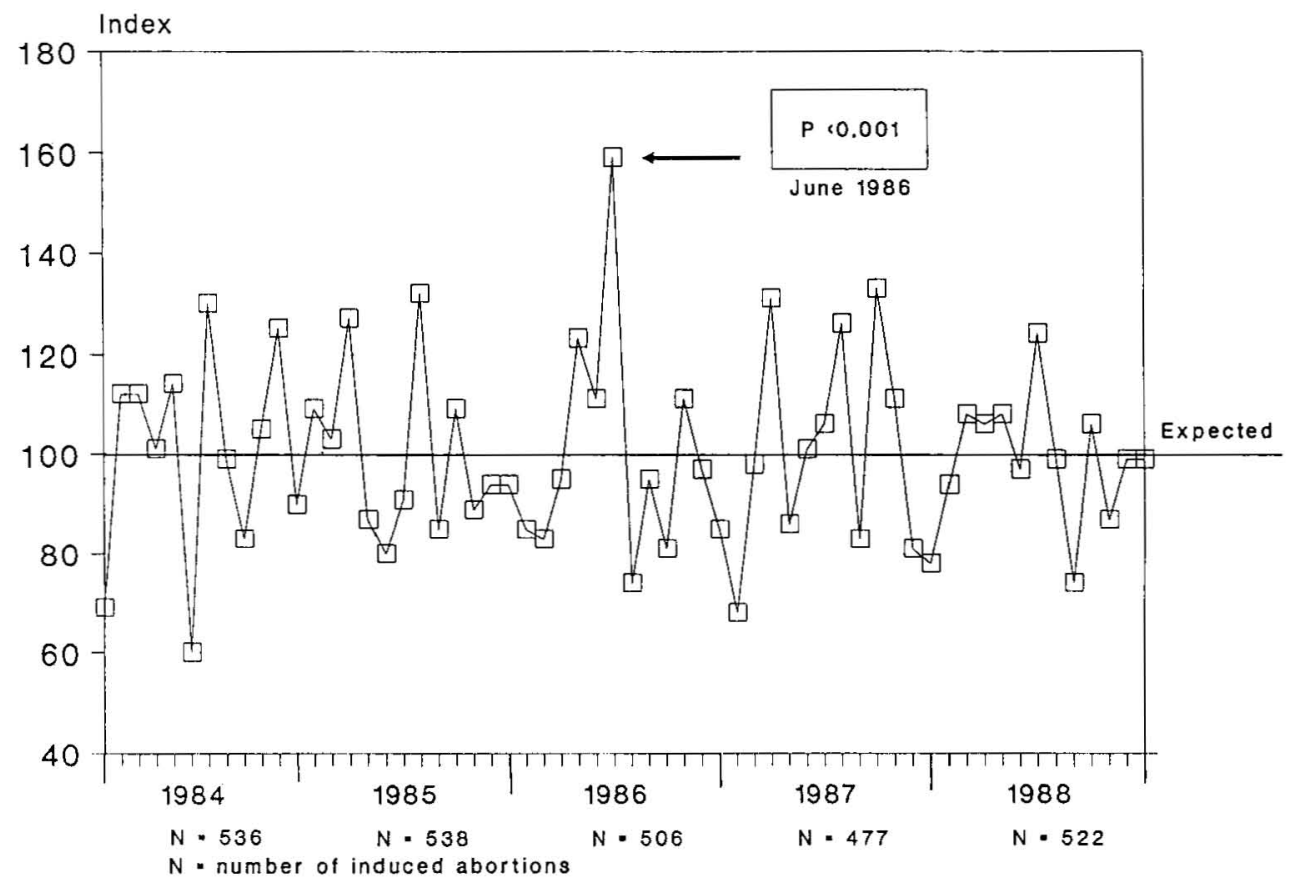

Figure 1. Index of monthly rate of induced abortions in Ticino (Switzerland) in 1984-1988. 
was recognized as negligible (4). Thus the "pressure" to induce abortion generated by the information given by the federal task force was not counterbalanced by official and authoritative information to the medical profession. This lack of information prevented physicians from providing pregnant women who inquired about a possible abortion due to the fear of fetal abnormalities with explanations in line with the actual situation until June $1986(5-8)$. Therefore it might be possible that several wanted pregnancies were interrupted by legal abortion.

We propose that this "one-way" information could probably be considered an additional explanation for the Bertollini et al findings.

\section{References}

1. Bertollini R, Di Lallo D, Mastroiacovco P, Perucci CA. Reduction of births in Italy after the Chernobyl accident. Scand J Work Environ Health 1990;16:96-101.

2. Domenighetti G, Perucchi M. Dopo Chernobyl: una sindrome di panico? Informazioni statistiche 1989;9:7-18.

3. Adler NE, David HP, Major BN et al. Psychological responses after abortion. Science 1990;248:41-4.
4. Office fédéral de la santé publique. Tschernobyl: risques liés aux radiations et leur problématique. Bern: Office fédéral de la santé publique, 1987.

5. Brent RL. Radiation teratogenesis. Teratology 1980;28198.

6. BEIR III: National Research Council, Advisory Committee on the Biological Effects of Ionizing Radiations. The effects of exposure to low levels of ionizing radiation. Washington DC: National Academy Press, National Academy of Science, 1980.

7. Brent RL. Xray, microwave and ultrasound: the real and unreal hazards. Pediatr Ann 1980;9:43-7.

8. Stieve FE. Exchange and transfer mechanisms of radioactive compounds between the mother and the developing offspring in utero: review of the experimental literature. In: Stieffer C, Patrick G, ed. Effects of prenatal irradiation with special emphasis on late effects. EULEPSymposium 29 July 1982 Bordeaux. 1984:159-81. (EURReport 8067.)

Manuela Perucchi, Gianfranco Domenighetti Department of Social Affairs

Cantonal Health Office

Via Orico 5

6501 Bellinzona, Switzerland 